\title{
Inhibition of IgE-mediated mast cell activation by the paired Ig-like receptor PIR-B
}

\author{
Takahiro Uehara, ${ }^{1}$ Mathieu Bléry, ${ }^{2}$ Dong-Won Kang, ${ }^{3}$ Ching-Cheng Chen, ${ }^{4}$ Le Hong Ho, ${ }^{5}$ \\ G. Larry Gartland, ${ }^{4} \mathrm{Fu}$-Tong Liu, ${ }^{6}$ Eric Vivier, ${ }^{2}$ Max D. Cooper ${ }^{1,5,7}$ and Hiromi Kubagawa ${ }^{3}$ \\ ${ }^{1}$ Division of Developmental and Clinical Immunology, Department of Medicine, University of Alabama at Birmingham, \\ Birmingham, Alabama, USA \\ ${ }^{2}$ Centre d'Immunologie de Marseille-Luminy, CNRS-INSERM-Universite de la Méditerrannée and \\ Institut Universitaire de France, Marseille, France \\ ${ }^{3}$ Division of Developmental and Clinical Immunology, Department of Pathology, and \\ ${ }^{4}$ Division of Developmental and Clinical Immunology, Department of Microbiology, University of Alabama at Birmingham, \\ Birmingham, Alabama, USA \\ ${ }^{5}$ Howard Hughes Medical Institute, Birmingham, Alabama, USA \\ ${ }^{6}$ Division of Allergy, La Jolla Institute for Allergy and Immunology, San Diego, California, USA \\ ${ }^{7}$ Division of Developmental and Clinical Immunology, Department Pediatrics, University of Alabama at Birmingham, \\ Birmingham, Alabama, USA
}

Address correspondence to: Hiromi Kubagawa, Division of Developmental and Clinical Immunology,

Department of Pathology, WTI Room 378, University of Alabama at Birmingham, Birmingham, Alabama 35294-3300, USA. Phone: (205) 975-7201; Fax: (205) 975-7218; E-mail: hkubagawa@ccc.uab.edu.

Takahiro Uehara, Mathieu Bléry, and Dong-Won Kang contributed equally to this work.

Received for publication January 10, 2001, and accepted in revised form August 21, 2001.

The potential of the paired Ig-like receptors of activating (PIR-A) and inhibitory (PIR-B) types for modifying an IgE antibody-mediated allergic response was evaluated in mouse bone marrow-derived mast cells. Although mast cells produced both PIR-A and PIR-B, PIR-B was found to be preferentially expressed on the cell surface, where it was constitutively tyrosine phosphorylated and associated with intracellular SHP-1 protein tyrosine phosphatase. PIR-B coligation with the IgE receptor (FcERI) inhibited IgE-mediated mast cell activation and release of serotonin. Surprisingly, the inhibitory activity of PIR-B was unimpaired in SHP-1-deficient mast cells. A third functional tyrosine-based inhibitory motif, one that fails to bind the SHP-1, SHP-2, and SHIP phosphatases, was identified in parallel studies of FcERI-bearing rat basophilic leukemia (RBL) cells transfected with constructs having mutations in the PIR-B cytoplasmic region. These results define the preferential expression of the PIR-B molecules on mast cells and an inhibitory potential that can be mediated via a SHP-1-independent pathway.

J. Clin. Invest. 108:1041-1050(2001). DOI:10.1172/JCI200112195.

\section{Introduction}

The paired Ig-like receptors of activating (PIR-A) and inhibitory (PIR-B) types were originally identified in mice on the basis of limited homology with the human IgA Fc receptor (FcoR) $(1,2)$. Their human counterparts are considered to be the activating and inhibitory types of leukocyte Ig-like receptors/CD85 (3-6). PIR-A and PIR-B have been defined as cell surface glycoproteins with similar extracellular regions (>92\% homology) containing six Ig-like domains, and distinctive transmembrane and cytoplasmic regions. PIR-A isoforms with slightly different sequences are encoded by the six or more Pira genes, whereas the invariant PIR-B molecule is encoded by a single Pirb gene $(1,2,7,8)$. The PIR-A proteins have a short cytoplasmic tail and a charged arginine residue in their transmembrane domain that facilitates noncovalent association with a transmembrane adaptor molecule, the $\mathrm{Fc}$ receptor common $\gamma$ chain $(\mathrm{FcR} \gamma \mathrm{c})$, to form a cell activation complex (9-12). The PIR-B molecule contains an uncharged transmembrane segment and four potential immunoreceptor tyrosine-based inhibitory motifs (ITIMs) in the cytoplasmic tail. Two of the ITIM regions of PIR-B, when tyrosine phosphorylated, can recruit the protein tyrosine phosphatase SHP-1, and possibly SHP-2 as well, to inhibit cell activation (10, 13-15), but these carboxy terminal ITIMs do not appear to account for all of the PIR-B inhibitory activity $(13,14)$. PIR-A and PIR-B are expressed by many types of hemopoietic cells, including B lymphocytes, dendritic cells, monocyte/macrophages, granulocytes, megakaryocytes/platelets, and mast cells $(11,16)$. Interestingly, the PIR-B molecules on freshly isolated B lymphocytes and macrophages have been found to be constitutively tyrosine phosphorylated, but they are rarely tyrosine phosphorylated on corresponding cell lines before their ligation by antibody (17). The reduced levels of PIR-B tyrosine phosphorylation found in $\beta 2$ microglobulindeficient mice suggest that MHC class I or class I-like molecules may serve as natural PIR ligands (17).

Mast cells are important mediators of allergic responses. They are generated in the bone marrow, circulate as immature precursors, and migrate into various tissue 
sites where they undergo terminal differentiation. Basophils also develop in the bone marrow, but they circulate as fully functional granulated cells that migrate into tissues in response to inflammation. Both types of cells contain metachromatic granules loaded with histamine, serotonin, and other biologically active products. They express high-affinity IgE receptors (FcERI) and low-affinity IgG receptors (FcyRIII), as well as receptors for multiple cytokines and growth factors. Upon activation by contact with allergens, the IgE antibodysensitized mast cells release the pharmacologically active mediators stored in their granules, resulting in clinical manifestations of type I hypersensitivity (18).

Information about the basic biology of mast cells and basophils has been gained largely through studies of bone marrow-derived mast cells (18) and the rat basophilic leukemia cell line (RBL-2H3). The RBL-2H3 cell line has been particularly useful in evaluating the activating and inhibitory potential of PIR-A and PIR-B in transfection studies using chimeric constructs (10, 13), but the biochemical nature and functional properties of native PIR molecules on the mast cells have not been examined previously. These issues have been addressed in the present studies of cultured mast cells of bone marrow and splenic origin. In parallel studies, the RBL-2H3 cell line was used to refine the definition of PIR-B-inhibitory motifs.

\section{Methods}

Mice. Four- to 8-week-old C57BL/6 (H-2 $\left.{ }^{\mathrm{b}}\right), \mathrm{C} 3 \mathrm{H} / \mathrm{HeJ}$ $\left(\mathrm{H}-2^{\mathrm{k}}\right)$, and $\mathrm{BALB} / \mathrm{cJ}\left(\mathrm{H}-2^{\mathrm{d}}\right)$ mice were purchased from The Jackson Laboratory (Bar Harbor, Maine, USA). $\mathrm{C} 3 \mathrm{H} / \mathrm{HeJ}$ mice heterozygous for motheaten mutation $(m e /+)$, kindly provided by K.A. Siminovitch (Mount Sinai Hospital, Toronto, Ontario, Canada), were bred to generate me homozygous mice (me/me). The me mutation status was identified by genomic PCR using diagnostic primers as described previously (19).

IL-3-induced mast cell cultures. Bone marrow cells were obtained from the femurs of adult C57BL $/ 6, \mathrm{C} 3 \mathrm{H} / \mathrm{He}$, and BALB/cJ mice. Splenic cells were obtained from neonatal motheaten $(\mathrm{me} / \mathrm{me})$ and wild-type $(+/+)$ littermate mice. After lysing the erythrocytes with $0.15 \mathrm{M}$ ammonium chloride solution, bone marrow and splenic cells were cultured at a cell concentration of $2 \times 10^{5} / \mathrm{ml}$ in RPMI 1640 medium containing $10 \%$ FCS (HyClone Laboratories, Logan, Utah, USA), penicillin $(100 \mathrm{U} / \mathrm{ml})$, streptomycin $(100 \mu \mathrm{g} / \mathrm{ml}), 50 \mu \mathrm{M} 2-\mathrm{ME}$, $1 \mathrm{mM}$ sodium pyruvate, $10 \mathrm{mM}$ HEPES, and mouse rIL-3 (4 ng/ml; R\&D Systems Inc., Minneapolis, Minnesota, USA). The marrow-derived nonadherent cells were transferred weekly into new culture flasks over a 4- to 10-week culture interval. Bone marrow mast cell cultures were established from FcERI $\alpha$ chain-deficient mice (20) and control littermates in some experiments. Splenic nonadherent cells were similarly transferred every 3 days for the first 2 -week period, then weekly. Morphology of the cultured cells was examined by staining cell smears with Giemsa or toluidine. The
WEHI-3 myeloid cell line obtained from American Type Culture Collection (Rockville, Maryland, USA) was maintained in the same medium without rIL-3.

Immunofluorescence analysis. Cells were incubated with aggregated human IgG to block Fc $\gamma \mathrm{R}$ before staining for 20 minutes at $4^{\circ} \mathrm{C}$ with a combination of PE-labeled rat anti-PIR mAb (6C1 clone, $\gamma 1 \kappa$ isotype; ref. 11) and FITC-labeled mAb's specific for the following antigens: CD13, CD69, Fc $\gamma \mathrm{RII} / \mathrm{III}, \mathrm{Gr}-1$, Mac1/CR3/CD11b, B220/CD45R, or MHC class II (PharMingen, San Diego, California, USA). Isotypematched mAb's with irrelevant specificity (PharMingen) and the $\operatorname{IgG}$ fraction from normal rat sera, purified by DE-52 ion exchange cellulose column chromatography, were used as controls. Other reagents included biotinylated rat $\mathrm{mAb}$ 's specific for c-kit (ACK-2, $\gamma 2 b \kappa ;$ ref. 21), a gift of S. Nishikawa (Kyoto University, Kyoto, Japan), and for CD40 (FGK45, IgGK; ref. 22), a gift of J. Anderson (Basel Institute for Immunology, Basel, Switzerland). Allophycocyanin-labeled (APC-labeled) streptavidin was used as a developing reagent. For the detection of FcERI, cells were incubated with $5 \mu \mathrm{g} / \mathrm{ml}$ of rat IgE anti-DNP mAb (Zymed Laboratories Inc., South San Francisco, California, USA) followed by FITC-labeled goat anti-rat Ig antibodies (Southern Biotechnology Associates, Birmingham, Alabama, USA). Stained cells were analyzed with a FACSCalibur flow cytometer (Becton Dickinson Immunocytometry Systems, San Jose, California, USA).

Immunoprecipitation analysis of cell surface and intracellular proteins. Viable cells $\left(3 \times 10^{7}\right)$ were surface radiolabeled with $1 \mathrm{mCi}$ of $\mathrm{Na}^{125}$ I by lactoperoxidase catalysis and solubilized in $\sim 500 \mu \mathrm{l}$ of $1 \%$ NP-40 lysis buffer containing various protease inhibitors as described elsewhere $(11,17)$. The ultracentrifuged membrane lysates were examined by a solid-phase immunoisolation technique. In brief, microtiter plates precoated with goat anti-rat Ig antibodies (Southern Biotechnology Associates) were incubated with rat anti-PIR (6C1) or isotypematched control mAb before overnight incubation with membrane lysates at $4^{\circ} \mathrm{C}$. Other rat anti-PIR mAb's and affinity-purified rabbit anti-PIR antibodies were used in some experiments to coat the microtiter plates. Bound proteins were dissociated by addition of $2 \%$ SDS, resolved on SDS-PAGE (10\% acrylamide) under reducing and nonreducing conditions, and the dried gels were exposed to $\mathrm{x}$-ray films. In some experiments, mast cells $\left(1.4 \times 10^{8}\right)$ were metabolically labeled for 18 hours with a mixture of ${ }^{35} \mathrm{~S}$-Met and ${ }^{35} \mathrm{~S}$-Cys ( $3 \mathrm{mCi}, 43.5$ TBq/mmol; NEN Life Science Products Inc., Boston, Massachusetts, USA) and ${ }^{35}$ S-Cys (500 $\mu \mathrm{Ci}, 39.8 \mathrm{TBq} / \mathrm{mmol}$; NEN Life Science Products Inc.), lysed, and incubated with streptavidin-coupled Sepharose 4B beads containing biotinylated phosphopeptides (15 mers) that correspond to the PIR-B cytoplasmic tyrosine (Y713, Y742, Y770, Y794, Y824) regions or to the Fc $\gamma$ RIIB ITIM, before SDS-PAGE analysis as described previously (13). 
Protein blot analysis. Cells $\left(3 \times 10^{7}\right)$ were solubilized in lysis buffer supplemented with $2 \mathrm{mM}$ sodium orthovanadate and $50 \mathrm{mM}$ sodium fluoride (17). Proteins in the cell lysates that were immunoadsorbed with antiPIR or control mAb's or with streptavidin-coupled beads containing the biotinylated PIR-B phosphopeptides were resolved on SDS-PAGE and transferred onto nitrocellulose membranes by electroblotting. After soaking in 3\% BSA in PBS containing $0.05 \%$ Tween-20, membranes were incubated with HRP-labeled mouse anti-phosphotyrosine mAb (4G10; Upstate Biotechnology Inc., Lake Placid, New York, USA) or with rabbit antibodies specific for protein tyrosine phosphatase SHP-1 (Upstate Biotechnology Inc.) or SHP-2 (Santa Cruz Biotechnology, Santa Cruz, California, USA) or for inositol polyphosphate 5-phosphatase SHIP (Santa Cruz Biotechnology). In some experiments, mouse anti-SHP-2 mAb (Transduction Laboratories, Lexington, Kentucky, USA) and HRP-labeled goat anti-mouse IgG antibody (Southern Biotechnology Associates) were used. For rabbit antibodies, HRP-labeled goat anti-rabbit Ig antibody $(0.1 \mu \mathrm{g} / \mathrm{ml}$; Southern Biotechnology Associates) was used as a developing reagent before visualization by enhanced chemiluminescence employing the oxidation of luminol in the presence of phenols (Amersham Life Science, Buckinghamshire, United Kingdom). Membranes were reblotted with rabbit anti-PIR antiserum (1:4,000 dilution) to detect PIR-A and PIR-B molecules.

RT-PCR analysis. Total RNA was extracted from cultured mast cells and control cell lines $\left(10^{7}\right.$ cells) by the TriReagent method (Molecular Research Center Inc., Cincinnati, Ohio, USA). Two micrograms of RNA were converted to first-strand cDNA with oligo (dT) ${ }_{12-18}$ primers and SuperScript RNase H ${ }^{-}$RT (Life Technologies Inc., Rockville, Maryland, USA), and amplified with a common forward primer (5'-CCTGTGGAGCTCACAGTCTCAG- $3^{\prime}$ ), and the PIR-A specific ( $5^{\prime}$-CCCAGAGTGTAGAACATTGAAGATG-3') or PIR-B specific (5'GTGTTCAGTTGTTCCCTTGACATGA- $3^{\prime}$ ) reverse primers. These primers correspond to the $3^{\prime}$ end of D6 of PIR-A and PIR-B and to the cytoplasmic regions of PIR-A and PIR-B, respectively, and yield fragments of $252 \mathrm{bp}$ for PIR-A and $470 \mathrm{bp}$ for PIR-B (1). Each amplification reaction included 30 cycles of denaturation at $94^{\circ} \mathrm{C}$ for 1 minute, annealing at $60^{\circ} \mathrm{C}$ for 1 minute, and extension at $72^{\circ} \mathrm{C}$ for 1 minute. A final extension was performed at $72^{\circ} \mathrm{C}$ for 5 minutes. Amplification of actin transcripts with the primers ( $5^{\prime}$-ATTGAACATGGCATTGTTACC- $3^{\prime}$ and $5^{\prime}$-GGCATACAGGGACAGCACAGC- $3^{\prime}$ ) was also performed as a control. Amplified products were electrophoresed in $1.5 \%$ agarose and stained with ethidium bromide.

$\mathrm{Ca}^{2+}$ mobilization analysis. Intracellular $\mathrm{Ca}^{2+}$ concentrations were measured after PIR and/or FceRI crosslinkage on mast cells as described elsewhere (13). Briefly, mast cells were loaded with Indo-1/AM (1 $\mu \mathrm{g} / \mathrm{ml}$; Calbiochem-Novabiochem Corp., San Diego, California, USA) in the presence or absence of rat $\operatorname{IgE}$
anti-DNP $\mathrm{mAb}(1 \mu \mathrm{g} / \mathrm{ml})$ for 30 minutes at $37^{\circ} \mathrm{C}$, resuspended at $10^{6}$ cells $/ \mathrm{ml}$ either in HBSS containing $5 \% \mathrm{FCS}$ or $\mathrm{Ca}^{2+}$-free HBSS containing $1 \mathrm{mM} \mathrm{MgCl}_{2}$ and were incubated first with $\mathrm{F}\left(\mathrm{ab}^{\prime}\right)_{2}$ fragments of the rat anti-PIR mAb (10.1 clone; $\gamma 2 \mathrm{~b} \kappa ; 20 \mu \mathrm{g} / \mathrm{ml}$ ) and then with $\mathrm{F}\left(\mathrm{ab}^{\prime}\right)_{2}$ fragments of rabbit anti-rat Ig antibody $(50 \mu \mathrm{g} / \mathrm{ml}$; Southern Biotechnology Associates) as a cross-linker. Purity of the $\mathrm{F}\left(\mathrm{ab}^{\prime}\right)_{2}$ reagents was established by SDS-PAGE analysis. An intact rat mAb (1D6 clone; $\gamma 2 \mathrm{a}$ ), against an undefined cell surface component on mouse cells, including mast cells, was used as a control for the 10.1 anti-PIR mAb. The $395 / 510 \mathrm{~nm}$ fluorescence ratio for the dye-loaded viable cells was determined with a FACStar Plus flow cytometer (Becton Dickinson Immunocytometry Systems) equipped with an Enterprise laser (Coherent Laser Group, Santa Clara, California, USA) regulated at $40 \mathrm{~mW}$ UV.

Serotonin-release assay. IgE-mediated serotonin release assay was performed according to methods described previously (13), with the following minor modifications. IL-3-induced mast cells $\left(1 \times 10^{6}\right.$ cells $\left./ \mathrm{ml}\right)$ were incubated with $5-\left[1,2-{ }^{3} \mathrm{H}(\mathrm{N})\right]$-hydroxytryptamine binoxalate ( $5 \mu \mathrm{Ci} / \mathrm{ml} ; 37,000 \mathrm{MBq}$; NEN Life Science Products Inc.) for 5 hours at $37^{\circ} \mathrm{C}$, washed, and reincubated for an additional 1 hour at $37^{\circ} \mathrm{C}$ to reduce background radioactivity. Thirty microliters of ${ }^{3} \mathrm{H}$-serotonin-loaded mast cells $\left(1.4 \times 10^{7}\right.$ cells $\left./ \mathrm{ml}\right)$ were plated in 96-well plates that contained $10 \mu \mathrm{l}$ of rat IgE anti-DNP mAb $(25 \mu \mathrm{g} / \mathrm{ml})$ and $10 \mu \mathrm{l}$ of various concentrations $(0.5-50$ $\mu \mathrm{g} / \mathrm{ml})$ of $\mathrm{F}\left(\mathrm{ab}^{\prime}\right)_{2}$ fragments of rat anti-PIR $\mathrm{mAb}$ in triplicate, incubated for 30 minutes at $4{ }^{\circ} \mathrm{C}$, washed, and resuspended in $25 \mu \mathrm{l}$ of culture medium. The 1D6 rat $\mathrm{mAb}$ (intact form) was used as a control antibody. Antibody-primed mast cells were challenged with $25 \mu$ of $\mathrm{F}\left(\mathrm{ab}^{\prime}\right)_{2}$ fragments of rabbit anti-rat Ig antibody (40 $\mu \mathrm{g} / \mathrm{ml})$ for $30-60$ minutes at $37^{\circ} \mathrm{C}$. In other experiments, DNP-coupled human serum albumin and goat anti-rat IgG antibody were used to aggregate separately the IgE and PIR receptors. The reactions were terminated by adding $50 \mu \mathrm{l}$ of cold HBSS and centrifugation. ${ }^{3} \mathrm{H}$-Serotonin in the supernatants was measured by a liquid scintillation counter. The total incorporation of ${ }^{3} \mathrm{H}$-serotonin was determined by lysis of unprimed cells with $1 \%$ SDS/1\% NP-40, and the percent of serotonin release was defined as: $100 \times(\mathrm{cpm}$ of supernatants $\div$ $\mathrm{cpm}$ of total incorporation). For cells transfected with FcyRIIB/PIR-B chimeric constructs, mouse IgE antiTNP mAb (2682-1), rat anti-mouse Fc $\gamma$ RII/III mAb $(2.4 \mathrm{G} 2 ; \gamma 2 \mathrm{b \kappa})$, and $\mathrm{F}\left(\mathrm{ab}^{\prime}\right)_{2}$ fragments of goat antimurine Ig antibodies (Immunotech, Marseille, France) were used to ligate FceRI and FcyRIIB/PIR-B as described elsewhere (13).

Constructs. cDNA constructs generated from a pNTNeo plasmid included a chimeric cDNA encoding the extracellular, transmembrane, and the first six amino acids (KKKQVP; one-letter code) of the cytoplasmic tail of the mouse FcrRIIB1, fused with the cytoplasmic region of the mouse PIR-B (Fc $\gamma$ RIIB/PIR-B) as described previously (13). The initial Fc $\gamma$ RIIB in 

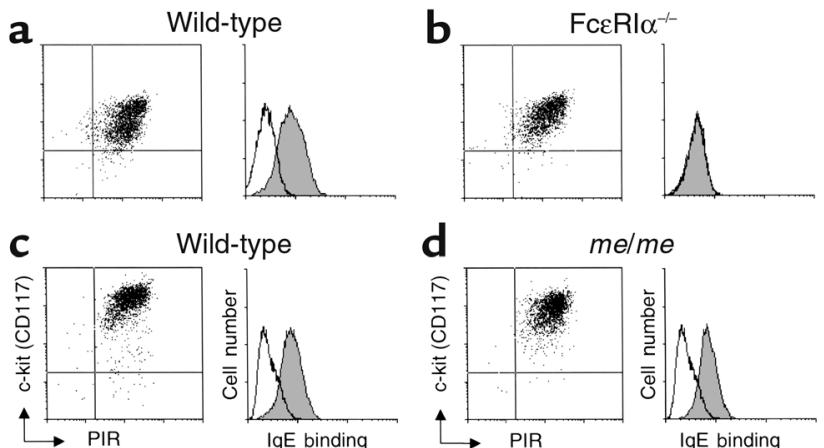

Wild-type
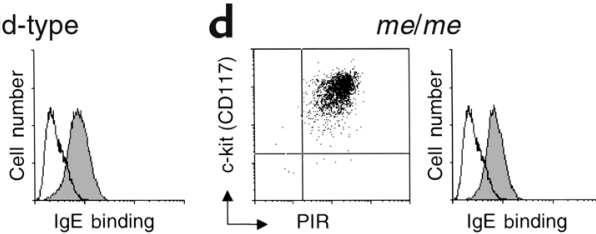

Figure 1

Cell surface expression of PIR molecules on cultured mast cells. Nonadherent cells from the bone marrow of (a) wild-type mice $(\mathrm{C} 57 \mathrm{BL} / \mathrm{cJ})$ and (b) FcERI $\alpha^{-1-}$ mice and from the neonatal spleens of (c) wild-type mice $(\mathrm{C} 3 \mathrm{H} / \mathrm{HeJ})$ and $(\mathbf{d}) \mathrm{me} / \mathrm{me}$ mice were cultured for 6 weeks with rIL-3. Cells were sequentially incubated with the PE-labeled 6C1 antiPIR mAb, biotinylated ACK-2 anti-c-kit mAb, and APC-labeled streptavidin or with rat IgE anti-DNP mAb (dark histogram) and FITClabeled goat anti-rat Ig antibodies before analysis by flow cytometry. Isotype-matched control rat mAb's were used to set the quadrants for immunofluorescence analysis, and unstained background controls are indicated by open histograms.

pNT-Neo vector was provided by $\mathrm{P}$. Bruhns and $\mathrm{M}$. Daëron (Institut Curie, Paris, France; ref. 23). Deletion and point-mutation constructs were generated by $\mathrm{PCR}$ directed mutagenesis of the Fc $\gamma$ RIIB/PIR-B construct. Each point mutation involved a tyrosine $(\mathrm{Y})$ replacement by phenylalanine $(F)$. Fidelity of the constructs was verified by sequencing.

Transfection. The RBL-2H3 rat basophilic leukemia cell line cultured in DMEM supplemented with $10 \%$ FCS, penicillin $(100 \mathrm{IU} / \mathrm{ml})$ and streptomycin $(100$ $\mu \mathrm{g} / \mathrm{ml})$ was transfected with different cDNA constructs by electroporation as described previously (13). Stable transfectants were established by culture in the presence of G418 $(1 \mathrm{mg} / \mathrm{ml})$.

\section{Results}

Characterization of mast cells derived from bone marrow and splenic progenitors. Nonadherent bone marrow cells from normal adult mice (BALB/c, C57BL/6, C3H/He) and from FceRI $\alpha$ chain-deficient (FcERI $\alpha^{-/}$) mice were cultured with rIL-3 for 4-10 weeks to generate mast cells; more than $95 \%$ of the cells in these cultures expressed high levels of the c-kit receptor tyrosine kinase (CD117) and the capacity to bind IgE (Figure 1). As anticipated, the c-kit ${ }^{+}$mast cells from FceRI $\alpha^{-/-}$mice did not exhibit IgE binding. Morphological analysis of the cultured cells indicated the presence of toluidine blue-stained granules characteristic of basophils and mast cells. The cells also expressed aminopeptidase N (CD13), lowaffinity receptors for IgG (FcyRII/III) and the CD69 early-activation antigen, but were negative for Mac1/CD11b, B220/CD45R, MHC class II, granulocyte differentiation antigen (Gr-1), and the CD40 TNF superfamily member, a phenotypic profile that is char- acteristic for IL-3-induced, bone marrow-derived mast cells $(18,24)$. Importantly for our studies, the IL3 -induced mast cells from normal and FceRI $\alpha^{-/-}$mice expressed cell surface PIR proteins at relatively high levels (Figure 1, a and b).

Mast cell cultures were also derived from neonatal splenic progenitors in SHP-1-deficient motheaten $(\mathrm{me} / \mathrm{me})$ mice and control littermates because the $\mathrm{me} / \mathrm{me}$ defect leads to early death. Like the mast cells generated from adult bone marrow, the spleen-derived mast cells expressed cell surface PIR as well as c-kit, CD13, Fc $\gamma \mathrm{RII} / \mathrm{III}, \mathrm{CD} 69$, IgE binding capacity, and intracellular metachromatic granules (Figure 1, c and d).

Predominant expression of constitutively tyrosine-phosphorylated PIR-B on mast cells. In a previous analysis, both PIR-A and PIR-B transcripts were found to be expressed by the P815 mast cell line, although this cell appeared to express higher levels of PIR-B transcripts than PIR-A transcripts. When a similar RT-PCR analysis was conducted for the bone marrow-derived mast cells, both PIR-A and PIR-B transcripts were found in roughly equal abundance (Figure 2a).

An immunoprecipitation analysis of radiolabeled cell surface proteins was then performed with the 6C1 anti-PIR antibody. This antibody recognizes a common epitope on the D1 and D2 Ig-like ectodomains of PIR-A and PIR-B proteins that can be distinguished on the basis of their relative molecular masses (11). To compare the array of PIR molecules expressed on the different types of cells, nonadherent mast cells and adherent macrophages in the bone marrow-derived cultures were separated and their cell surface PIR proteins were analyzed along with those expressed by splenocytes, the majority of which were B lymphocytes. Both the 120-kDa PIR-B and 85-kDa PIR-A were precipitated from membrane lysates of surface iodinated splenocytes and macrophages, whereas only PIR-B molecules were detected in the membrane lysates of mast cells (Figure 2b). Given that FcR $\gamma c$ is required for the expression of functional PIR-A, limited FcR $\gamma c$ availability due to competition with the FceRI could account for the paucity of cell surface PIR-A expression. To test this possibility, the FceRI $\alpha^{-/}$ mice-derived mast cells were examined for their surface PIR expression. The results again indicated predominant expression of PIR-B on the surface of $\mathrm{FcERI}^{-/-}$mast cells, thereby suggesting that a limitation in the availability of $\mathrm{FcR} \gamma \mathrm{c}$ is unlikely to be the basis for the paucity of surface PIR-A on mast cells (Figure 2c, upper panel). The predominance of cell surface PIR-B was also observed for mast cells derived from splenic progenitors in neonatal me/me mice and control littermates (Figure 2c, lower panel) The PIR-B molecules on mast cells were also found to be constitutively tyrosine phosphorylated and to be associated with SHP-1 protein tyrosine phosphatase, except in mast cells from me/me mice. SHP-2 was not found to be associated with PIR-B in mast cells (data not shown), consistent with the results of an earlier 


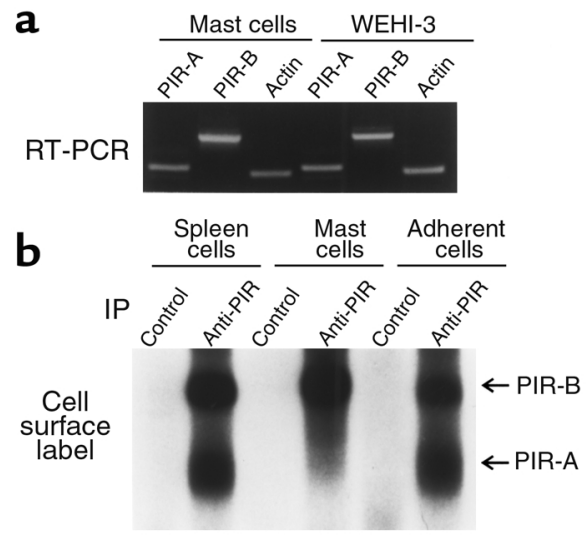

C
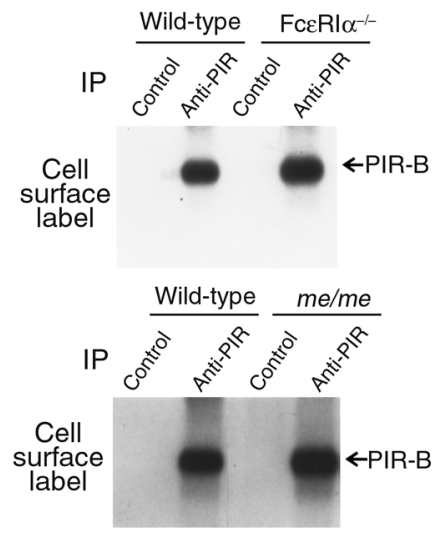

Figure 2

PIR expression by IL-3-induced mast cells. (a) RT-PCR analysis of PIR-A, $\mathrm{PIR}-\mathrm{B}$, and actin gene expression by $\mathrm{C} 3 \mathrm{H} / \mathrm{HeJ}$ bone marrow-derived mast cells and the WEHI- 3 myeloid cell line. The PCR products were electrophoresed in $1.5 \%$ agarose and stained with ethidium bromide. (b) Analysis of the PIR molecules on splenocytes, mast cells, and macrophages. Cell surface proteins were ${ }^{125}$-labeled, solubilized in $1 \%$ NP-40, and immunoadsorbed with 6C1 anti-PIR or an isotypematched control $\mathrm{mAb}$ before analysis by SDS-10\% PAGE under reducing conditions as described in Methods. (c) Analysis of PIR molecules on mast cells derived from adult bone marrow of FcERI $\alpha^{-/-}$mice and littermate controls (upper panel) and from neonatal spleens of $\mathrm{me} / \mathrm{me}$ mice and littermate controls (lower panel). lodinated cell surface PIR proteins were resolved on SDS-10\% PAGE under reducing conditions.

analysis of PIR-B molecules on splenic B lymphocytes and macrophages (17).

PIR-B-mediated inbibition of FcERI-induced $\mathrm{Ca}^{2+}$ mobilization and serotonin release. Because mast cells preferentially express PIR-B on their cell surfaces, examination of the functional consequence of PIR-A/PIR-B ligation with a nondiscriminative antibody is a more straightforward analysis than for the B lymphocytes and myeloid cells that express both PIR-A and PIR-B molecules on their cell surface. The effects of PIR-B cross-linkage on FceRI-mediated $\mathrm{Ca}^{2+}$ mobilization were examined initially as an early indicator of the cellular response. Ligation of FcERI on mast cells induced an immediate $\mathrm{Ca}^{2+}$ release from intracellular pools, followed by a sustained increase that may reflect the influx of extracellular $\mathrm{Ca}^{2+}$. Although PIR ligation alone had no demonstrable effect on intracellular $\mathrm{Ca}^{2+}$ levels, coligation of FceRI and PIR inhibited IgEinduced $\mathrm{Ca}^{2+}$ mobilization (Figure 3, upper panel). When this experiment was repeated in $\mathrm{Ca}^{2+}$-free media, IgE-induced $\mathrm{Ca}^{2+}$ mobilization was again inhibited by PIR-B and FceRI coligation (data not shown), thereby confirming that the PIR-B inhibition affects $\mathrm{Ca}^{2+}$ release from the intracellular pool.

When the effects of PIR-B cross-linkage on FceRImediated serotonin release were evaluated, PIR coligation with the FceRI inhibited this mast cell response in a dose-dependent manner (Figure 4, left panel). The inhibition was observed only when the PIR-B and FceRI were brought into physical proximity by ligation with a common secondary reagent. In a test of the PIR-B specificity of the inhibitory effect, coligation of FcERI with an unrelated cell surface molecule did not inhibit IgE-mediated serotonin release. Separate ligation of cell surface PIR-B and FceRI with individual secondary reagents also did not result in inhibition of the $\operatorname{IgE}-$ mediated serotonin release, and ligation of PIR-B alone did not induce serotonin release (data not shown). These findings collectively demonstrate the functional potential of PIR-B as a negative regulator of IgE-mediated mast cell activation.

SHP-1 is dispensable in the PIR-B inbibitory activity. In native $B$ cells and in transfected cell models, PIR-B has been shown to recruit the SHP-1 protein tyrosine phosphatase $(10,13-15)$. To test the requirement for SHP-1 in the PIR-B-mediated inhibition of FceRI signaling, we examined mast cells from SHP-1-deficient motheaten $(m e / m e)$ mice and normal littermate $(+/+)$ controls. To our surprise, IgE antibody-mediated intracellular $\mathrm{Ca}^{2+}$

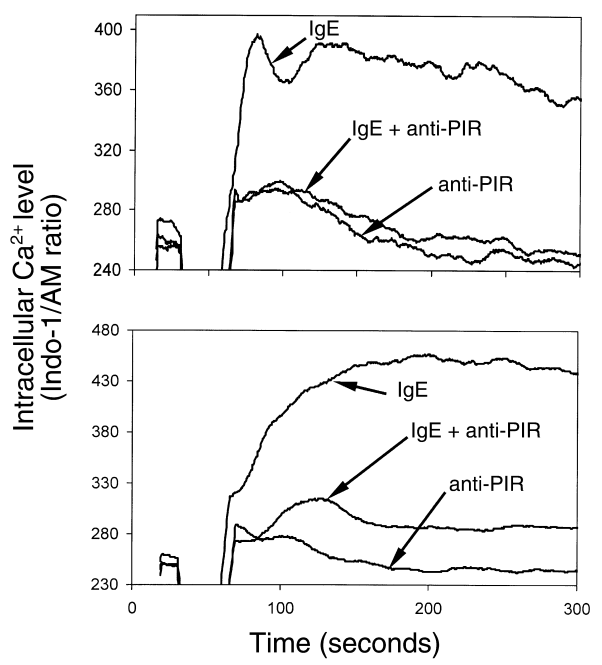

\section{Figure 3}

PIR-B inhibitory activity in FcERI-mediated $\mathrm{Ca}^{2+}$ mobilization. Indo$1 / A M$ dye preloaded mast cells from wild-type mice (upper panel) and motheaten mice (lower panel) were analyzed by flow cytometry for intracellular $\mathrm{Ca}^{2+}$ levels in the presence or absence (data not shown) of extracellular $\mathrm{Ca}^{2+}$. Cells were stimulated with rat IgE antiDNP (IgE), $F\left(a b^{\prime}\right)_{2}$ fragments of rat anti-PIR (anti-PIR), or both $m A b$ 's (IgE + anti-PIR). $F\left(a b^{\prime}\right)_{2}$ fragments of rabbit anti-rat Ig antibodies were used as the cross-linking reagent. 


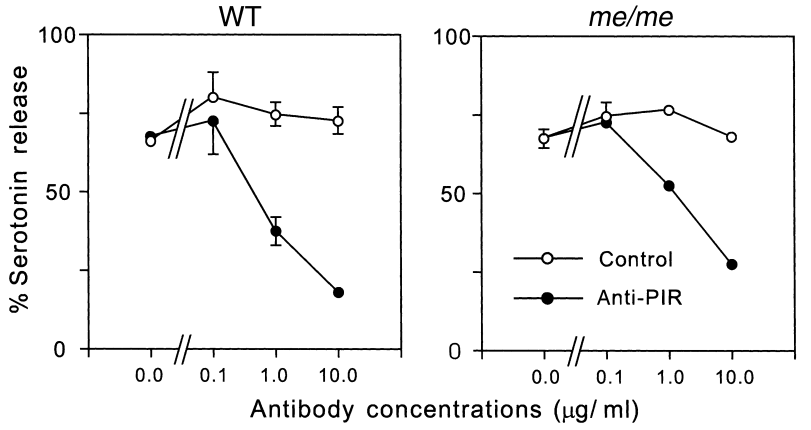

Figure 4

PIR-B inhibitory activity in FcERI-induced serotonin release. ${ }^{3} \mathrm{H}$-Serotonin preloaded mast cells from wild-type neonatal spleen (left) and motheaten mutant neonatal spleen (right) were incubated with rat IgE anti-DNP $m A b$ plus various concentrations of $F\left(a b^{\prime}\right)_{2}$ fragments of rat $m A b$ specific for PIR (filled circles) or unknown cell surface antigen (open circles). Antibody-primed cells were then triggered with $\mathrm{F}\left(\mathrm{ab} \mathrm{b}_{2}\right)_{2}$ fragments of rabbit anti-rat Ig antibody as a cross-linker, and the ${ }^{3} \mathrm{H}$-serotonin release was measured as described in Methods. The standard deviation from the mean (circle) is indicated by bars only for the points at which this value (1 SD) is greater than the circle radius.

mobilization and serotonin release were inhibited as efficiently by PIR-B and FceRI coligation on mast cells from SHP-1-deficient motheaten $(\mathrm{me} / \mathrm{me})$ mice as for mast cells from control $(+/+)$ littermates (Figure 3, lower panel; Figure 4, right panel). The absence of the $65-\mathrm{kDa}$ SHP-1 protein was confirmed by immunoprecipitation analysis of the motheaten-derived mast cells with anti-SHP-1 antibodies in these experiments.

When a search was conducted for the association of PIR-B with another protein tyrosine phosphatase in the motheaten-derived mast cells, the approximately $72-\mathrm{kDa}$ SHP-2 protein could not be found in PIR-B immunoprecipitates examined with two different SHP-2 specific antibodies, although SHP-2 protein is abundant in the mast cells and can be shown to bind to phosphopeptides representative of the two carboxy terminal PIR-B ITIMs (ref. 13; see below). To examine the possibility that SHP-2 may be recruited by PIR-B only after receptor cross-linkage in the absence of SHP-1, PIR-B immunoprecipitates were examined before and after PIR crosslinkage on the mast cells. However, SHP-2 association with PIR-B could not be detected even after receptor ligation in these experiments (data not shown). The SHIP inositol polyphosphate 5-phosphatase was also not found to be associated with the PIR-B molecules in the mast cells from me/me and control mice. These unanticipated results indicate that the PIR-B-mediated inhibition of IgE-induced responses in mast cells is not dependent on SHP-1, and also imply lack of dependence on SHP-2 or SHIP interaction.
Rather, the data raise the possibility that another, yet unidentified, inhibitory signaling element can participate in the PIR-B inhibitory function.

A third tyrosine-based motif in the PIR-B cytoplasmic tail mediates inhibitory function. The PIR-B protein contains five cytoplasmic tyrosine residues, four of which, Y713 (LYASV), Y742 (ETYAQV), Y794 (VTYAQL), and Y824 ( $\underline{S} V \underline{Y}$ ATL $)$, reside within ITIM-like sequences $(\mathrm{I} / \underline{\mathrm{V}} / \mathrm{L} / \underline{\mathrm{S}}-\mathrm{x}-\underline{\mathrm{Y}}-\mathrm{x}-\mathrm{x}-\underline{\mathrm{V}} / \underline{\mathrm{L}})$, whereas the other tyrosine, $\mathrm{Y} 770$ (TEYEQA), does not reside in an ITIM consensus sequence. In previous studies (13), phosphopeptides corresponding to the Y794 tyrosine- and Y824 tyrosine-based motifs were shown to bind SHP-1 and SHP-2 phosphatases derived from a B cell line, whereas phosphopeptides representing the other two ITIM candidates failed to bind either phosphatase. To test whether these relationships held true for mast cells, the cellular proteins in lysates of metabolically labeled and unlabeled mast cells were incubated with phosphopeptides containing the PIR-B tyrosine residues (Y713, Y742, Y770, Y794, Y824) or the FcyRIIB ITIM as a control. Although the FcyRIIB phosphopeptide bound multiple SHIP isoforms as well as SHP-1 and SHP-2, the two carboxy terminal PIR-B ITIM phosphopeptides (Y794 and Y824) again were found to bind both SHP-1 and SHP-2. Although the Y742 phosphopeptide failed to bind SHIP, SHP-1 or SHP-2, a protein of approximately $120 \mathrm{kDa}$ was instead found to be associated with this ITIM candidate (Figure 5).

Previous transfection studies have indicated that the two carboxy terminal PIR-B ITIMs (Y794 and Y824) are responsible for most, but not all, of the inhibitory capacity of PIR-B $(13,14)$. To determine whether the

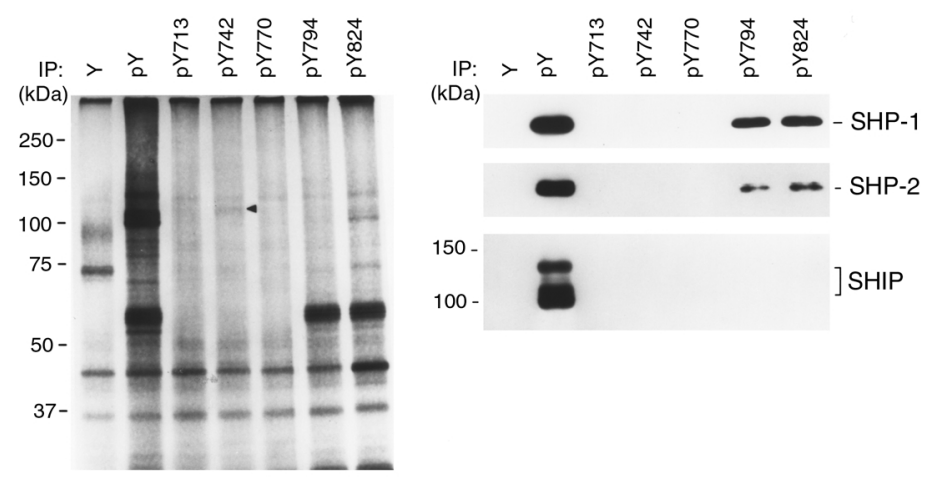

Figure 5

Analysis of mast cell proteins binding to PIR-B ITIM. Left panel: Metabolically labeled mast cell proteins were solubilized in 1\% NP-40 lysis buffer before incubation with streptavidin-coupled beads bearing biotinylated 15-mer peptides corresponding to the mouse FcyRIIB ITIM (tyrosine-phosphorylated, PY, or tyrosine-nonphosphorylated, $\mathrm{Y}$, as controls) and each of the tyrosine-phosphorylated and biotinylated PIR-B ITIM (pY713, pY742, pY770, pY794, pY824). Bound materials were resolved by SDS-8\% PAGE under nonreducing conditions before exposure to $x$-ray films. Arrowhead indicates $120-k D a$ protein band precipitated by the PY742 phosphopeptide. Right panel: Proteins isolated from mast cell lysates with the same phosphopeptides were resolved by SDS-PAGE before transfer onto membranes and immunoblotting with antibodies specific for SHP-1, SHP-2, or SHIP before visualization by enhanced chemiluminescence. 
other two tyrosine-based motifs, centered around Y713 and Y742, can also mediate PIR-B inhibitory activity, four additional chimeric constructs were prepared: (a) One encodes a short PIR-B cytoplasmic tail with a carboxy terminal deletion from five amino acids after Y742 (YY); (b) the second encodes a similar short PIR$\mathrm{B}$ cytoplasmic tail with a point mutation of $\mathrm{Y} 742 \mathrm{~F}(\mathrm{YF})$; (c) the third includes three point mutations, Y713F, $794 \mathrm{~F}$, and $\mathrm{Y} 824 \mathrm{~F}$, to allow evaluation of the role of Y742 (FYFF); and (d) the fourth encodes the shortest PIR-B cytoplasmic tail, rendered tyrosine-free by deleting the carboxy terminus from position 712 onward $(\Delta 712)$. These chimeric constructs were transfected into RBL-2H3 cells, and the resultant stable transfectants were shown by immunofluorescence to express levels of Fc $\gamma$ RIIB/PIR-B chimeric receptors comparable to that of the wild-type transfectant, except for the YF transfectant, where the Fc $\gamma R$ RIB/PIR-B level was higher (Figure 6). The cell surface levels of endogenous FcERI on the different transfectants were not altered.

These chimeric receptor transfectants were examined for their potential to inhibit the FceRI-mediated serotonin release. As previously shown (13), coligation of FceRI and the wild-type (YYYY) chimeric receptor effectively inhibited the IgE-mediated serotonin release (Figure 7). The YY-type chimeric receptor could also mediate significant inhibition over a wide range of IgE stimulation dosages, whereas the YF type chimeric receptor did not, even though the YF transfectant expressed higher levels of chimeric receptors than did the YY transfectant. The FYFF-type chimeric receptor mediated inhibition to a similar degree as did the YY-type chimeric receptor, thereby implicating the Y742-based motif in the inhibition. No inhibitory capability could be demonstrated for the $\Delta 712$-type chimeric receptor. These findings demonstrate that three of the four PIR-B ITIM candidates, namely the Y742-, Y794-, and Y824-based motifs, have inhibitory capability. The inhibitory function of the newly verified Y742-based ITIMs may involve the associated p120 molecule (see Figure 5).

\section{Discussion}

Several unanticipated features of the PIR-B inhibitory potential in mast cells are indicated in these studies. Although mast cells apparently produce PIR-A and PIR-B in similar amounts, the latter is preferentially expressed on the mast cell surface as a constitutively tyrosine phosphorylated molecule. Although the SHP-1 protein tyrosine phosphatase is normally associated with PIR-B molecules, surprisingly, this phosphatase appears to be entirely dispensable in the PIRB-mediated inhibition of IgE antibody-mediated mast cell activation. A third functional PIR-B ITIM identified in this study, the Y742-based ETYAQV motif, that failed to bind either protein tyrosine phosphatases (SHP-1 and SHP-2) or inositol polyphosphate 5-phosphatase (SHIP) $(8,10,13)$, was found to associate with another potential regulatory element, a presently unidentified protein of approximately $120 \mathrm{kDa}$.
Mast cells derived from bone marrow or splenic progenitors were found to produce the PIR-B and PIR-A transcripts in comparable levels, but an analysis of their cell surface expression indicated a striking prevalence of PIR-B. PIR-A could not be detected on the mast cells, whereas PIR-B was easily and consistently detected on the cell surface. Previous studies have indicated that an association with FcR $\gamma c$ homodimers is required for the normal expression of PIR-A molecules on the cell surface (11). As FcR $\gamma c$ is also an essential component of the high-affinity IgE receptor complex, FceRI (25), an inability to compete efficiently with the FceRI for a limited supply of FcR $\gamma c$ dimers could explain the paucity of PIR-A molecules that reach the mast cell surface. Indeed, previous studies have suggested competition between FceRI and Fc $\gamma$ RIII for limiting amounts of FcR $\gamma c$ (26, 27). Functional FcyRIII is not expressed on mast cells, as it is not efficiently associated with the FcR $\gamma c$ and thus
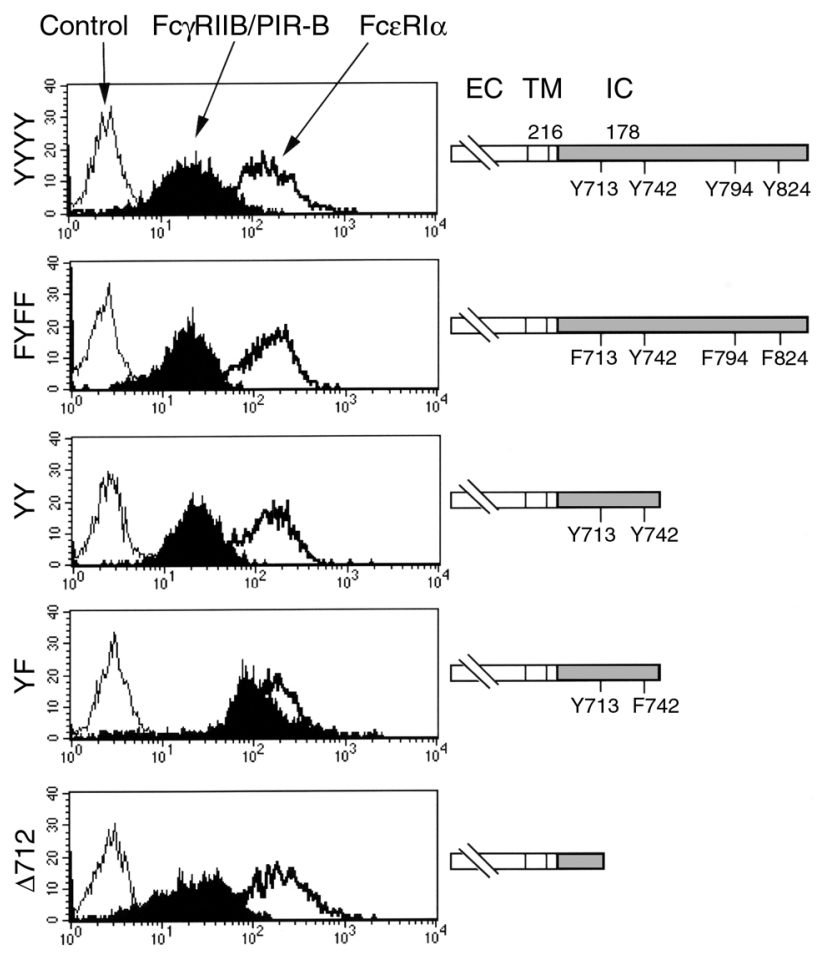

Figure 6

Comparison of surface expression of Fc $\gamma \mathrm{R} I I \mathrm{~B} / \mathrm{PIR}$ chimeric receptors among various stable transfectants. $\mathrm{RBL}-2 \mathrm{H} 3$ rat basophilic leukemia cells were transfected by electroporation with various types ( $\mathrm{YYY}$, FYFF, YY, YF, and $\Delta 712$ ) of chimeric construct (FcyRIIB/PIR-B). These constructs encode the extracellular (EC), transmembrane (TM), and the first six amino acids of the cytoplasmic tail of the mouse Fc $\gamma R$ RIIB1 (open portions of bars) and fused with different intracytoplasmic regions (IC) of the mouse PIR-B (filled portions of bars) as depicted in the right panel. Four cytoplasmic tyrosine $(Y)$ residues are also indicated. For the left panel, stably transfected cells were sequentially incubated with 2.4G2 rat mAb and FITC-labeled goat anti-rat Ig antibody (filled profile) or with BC4 mouse IgE mAb and FITC-labeled goat anti-mouse Ig antibody (thick line) in order to determine their cell surface levels of FcyRIIB/PIR-B chimeric receptors and endogenous FceRI by flow cytometry. Irrelevant mouse IgG (thin line) was used as a control to obtain a background staining. 


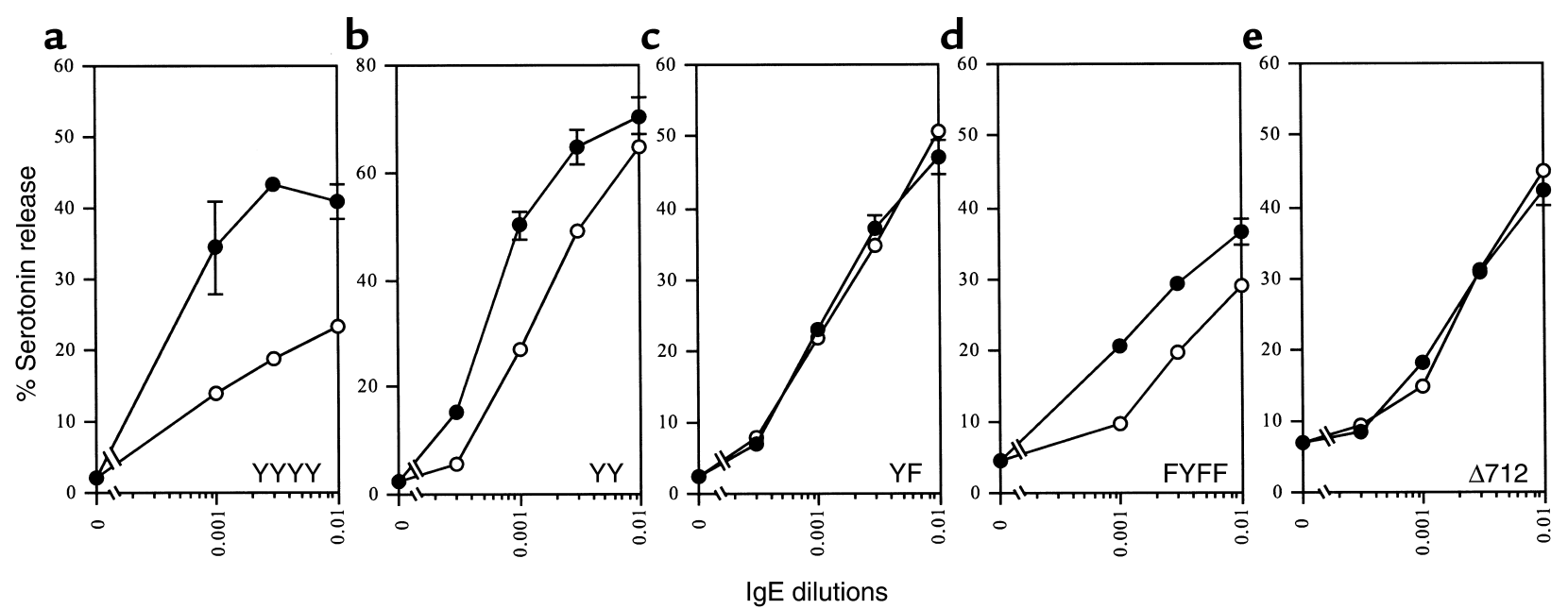

\section{Figure 7}

Inhibitory activity of Fc $\gamma$ RIIB/PIR-B chimeric receptors expressed by RBL transfected cells. RBL-2H3 cells transfected with the indicated Fc $\gamma$ RIIB/PIR-B constructs were incubated with various dilutions of mouse IgE in the absence (filled circles) or presence (open circles) of

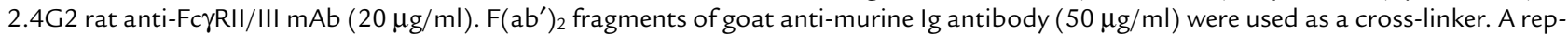
resentative result is shown as a mean $\pm 1 \mathrm{SD}$ (if the SD values are greater than the radius of circles) from at least three independent experiments. Statistical analysis revealed that inhibition is significant for $\lg E$ at 1:1,000 and 1:300 dilutions in $\mathbf{a}, \mathbf{b}$, and $\mathbf{d}$ (data not shown).

degraded intracellularly (26). Absence of FceRI $\alpha$ chain thus results in upregulation of FcyRIII-dependent mast cell responses (27). However, we found that FceRI $\alpha$ chain-deficient mast cells also lack detectable cell surface PIR-A expression, thereby suggesting that other regulatory mechanisms may account for the paucity of PIR-A on mast cells. The IL-3-induced mast cells should provide an ideal cell source to determine the regulatory mechanisms affecting the equilibrium of cell surface PIR-A and PIR-B expression.

The integrity of the PIR-B-mediated inhibition of IgE triggered $\mathrm{Ca}^{2+}$ mobilization and serotonin release in SHP-1-deficient mast cells was also unanticipated, because previous studies have suggested that the inhibitory activity of PIR-B is mediated primarily through its association with SHP- $1(13,14,17)$. The possibility was therefore considered that the inhibition seen in $m e / m e$ mast cells reflected artifactual co-cross-linkage of PIR-B with the Fc $\gamma$ RIIB via the intact antibodies used for coligating PIR-B and FceRI. Fc $\gamma$ RIIB has its own ITIM motif, through which it can interact with the SHIP inositol polyphosphate 5-phosphatase to inhibit cell activation (28-30). However, this explanation of our results was rendered unlikely by the observations that (a) intact $\operatorname{IgG}$ molecules could not be detected in the $\mathrm{F}\left(\mathrm{ab}^{\prime}\right)_{2}$ preparations of rat anti-PIR and rabbit anti-rat Ig antibodies that were used for receptor coligation, (b) inhibitory responses generated by PIR-B and Fc $\gamma$ RIIB are dissimilar in that PIR-B-mediated inhibition involves a blockage of $\mathrm{Ca}^{2+}$ release from intracellular stores (see Figure 3), whereas FcyRIIB-mediated inhibition involves blockage of $\mathrm{Ca}^{2+}$ influx (28), and (c) the coligation of FcERI and an unrelated molecule with an intact antibody failed to inhibit the IgE-mediated $\mathrm{Ca}^{2+}$ mobilization and serotonin release. The alternative possibility that the inhibitory activity of PIR-B could directly involve SHIP is rendered unlikely by the inability to identify an association between these two molecules in the present studies or in earlier analyses $(13-15,17)$.

Protein tyrosine phosphatase activity mediated by SHP-2 is a third possible explanation for the PIR-B inhibitory effect observed in SHP-1-deficient mast cells. In a previous analysis using a $\mathrm{B}$ cell line, we observed that SHP-1 and SHP-2 could bind to phosphopeptides corresponding to the two carboxyterminal ITIM (Y794 and Y824) in the PIR-B cytoplasmic tail (13). The present studies indicate that the PIR-B Y794 and Y824 phosphopeptides also associate with SHP-1 and SHP-2 in mast cells. However, in normal mast cells, splenic lymphocytes (17), and RBL-2H3 cells transfected with chimeric receptor (extracellular FcyRIIB/PIR-B cytoplasmic tail) constructs (13), we have consistently observed the association of PIR-B with SHP-1, and not with SHP-2. Nevertheless, when Maeda et al. used PIR-B constructs to transfect DT-40 chicken B cells deficient in SHP-1, SHP-2, or both, their results suggested that both the SHP- 1 and SHP- 2 phosphatases may participate in PIR-B-mediated inhibition (14). Although this interpretation could also explain our results with the motheaten (me/me) mast cells, PIRB-associated SHP-2 molecules were not demonstrable in mast cells from normal mice or the SHP-1-deficient motheaten mice. This raises the possibility that PIR-B signaling elements other than SHP-1, SHP-2, and SHIP contribute to the inhibitory function. Consistent with this hypothesis, Maeda et al. found residual PIR-B inhibitory activity in the SHP-1 and SHP-2 double-deficient DT40 cells, leading them to invoke the involvement of an additional SH2-containing protein(s) in mediating the PIR-B inhibitory signal (14). 
In this regard, a third functional ITIM in the PIR-B cytoplasmic tail is indicated by the present results. In addition to the two carboxy-terminal ITIM centering around the Y794 and Y824 residues, transfection experiments with constructs differing in the integrity of their PIR-B cytoplasmic region indicate that one of the more membrane proximal ITIM (Y742: ETYAQV) is capable of mediating inhibition of the FceRI-induced serotonin release. While the fourth candidate ITIM (Y713, SLYASV) matches the consensus sequence (I/V/L/S- $x-Y-x-x-V / L)$, no inhibitory activity could be demonstrated for a transfectant having an intact Y713based motif alone. Whether or not a given cytoplasmic tyrosine residue mediates an inhibitory signal therefore cannot be predicted entirely by sequence similarity with an ITIM consensus motif. The functional Y742-based motif matches the consensus ITIM motif, except for a charged glutamic acid in position -2 to the tyrosine. This charged amino acid could alter the properties of this motif relative to those of the consensus ITIM motif. The molecular mechanism through which which the Y742-based ITIM exerts its inhibitory function will be interesting to determine, especially in view of its inability to bind SHP-1, SHP-2, and SHIP $(8,10$, 13). Instead, the PIR-B Y742 phosphopeptide was found to bind a protein of approximately $120 \mathrm{kDa}$, the identity of which remains to be elucidated. This analysis suggests a further surprising feature of the PIR-B ITIM motifs in that they are able to mediate inhibition on their own and do not need to be present in tandem to mediate inhibition, as has been suggested for the ITIM in the killer Ig-like receptors (23).

While the ligands for the PIR molecules are unknown, our functional analysis indicates that PIR-B coligation can inhibit IgE antibody-mediated mast cell activation. PIR-B is thus the third ITIM-containing inhibitory receptor to be identified on murine mast cells, a trio including FcyRIIB and gp49B1 $(31,32)$. Multiple negative regulators may be needed for mast cells to attenuate their release of potent inflammatory mediators. In this regard, mast cells from Fc $\gamma$ RIIB-deficient mice have been found to be very sensitive to IgG-triggered degranulation (33). Moreover, these mice exhibit exaggerated anaphylactic susceptibility as well as enhanced humoral responses. It might be predicted that PIR-B-deficient mice will also exhibit enhanced type I hypersensitivity. Given that human basophils and mast cells express at least four ITIM-containing inhibitory receptors, the Fc $\gamma$ RIIB (34), the mast cell function-associated antigen (35), signal regulatory protein $\alpha$ (36) and the PIR relatives, Ig-like transcripts (also known as leukocyte Ig-like receptors, monocyte/macrophage Ig-like receptors, monocyte cDNA-18, and CD85) (3-6), mast cell modulation by these negative regulators could prove to be important in allergic disorders (for a review, see ref. 37).

\section{Acknowledgments}

The authors thank Pierre Bruhns and Marc Daëron for the Fc $\gamma$ RIIB construct; Shin-ichi Nishikawa and
Jan Anderson for ACK-2 and FGK45 mAb's; Katherine A. Siminovitch for motheaten heterozygous mice; Lan Yu for mast cell cultures; Frédéric Vely for phosphopeptides, E. Ann Brookshire and Marsha Flurry for help in preparing the manuscript; and Prescott Atkinson, Robert H. Carter, Glynn Dennis, and Louis B. Justement for helpful advice and criticism. This work was supported in part by Institut Universitaire de France (E. Vivier) and NIH grant AI42127 (H. Kubagawa). M.D. Cooper is a Howard Hughes Medical Institute Investigator.

1. Kubagawa, H., Burrows, P.D., and Cooper, M.D. 1997. A novel pair of immunoglobulin-like receptors expressed by B cells and myeloid cells. Proc. Natl. Acad. Sci. USA. 94:5261-5266.

2. Hayami, K.D., et al. 1997. Molecular cloning of a novel murine cellsurface glycoprotein homologous to killer cell inhibitory receptors. $J$. Biol. Chem. 272:7320-7327.

3. Samaridis, J., and Colonna, M. 1997. Cloning of novel immunoglobulin superfamily receptors expressed on human myeloid and lymphoid cells: structural evidence for new stimulatory and inhibitory pathways. Eur. J. Immunol. 27:660-665.

4. Cosman, D., et al. 1997. A novel immunoglobulin superfamily receptor for cellular and viral MHC class I molecules. Immunity. 7:273-282.

5. Wagtmann, N., Rojo, S., Eichler, E., Mohrenweiser, H., and Long, E.O. 1997. A new human gene complex encoding the killer cells inhibitory receptors and related monocyte/macrophage receptors. Curr. Biol. 7:615-618.

6. Arm, J.P., Nwankwo, C., and Austen, K.F. 1997. Molecular identification of a novel family of human Ig superfamily members that possess immunoreceptor tyrosine-based inhibition motifs and homology to the mouse gp49B1 inhibitory receptor. J. Immunol. 159:2342-2349.

7. Alley, T.L., Cooper, M.D., Chen, M., and Kubagawa, H. 1998. Genomic structure of PIR-B, the inhibitory member of the paired immunoglobulin-like receptor genes in mice. Tissue Antigens. 51:224-231.

8. Yamashita, Y., et al. 1998. Genomic structures and chromosomal location of $\mathrm{p} 91$, a novel murine regulatory receptor family. J. Biochem. (Tokyo). 123:358-368.

9. Maeda, A., Kurosaki, M., and Kurosaki, T. 1998. Paired immunoglobulin-like receptor (PIR)-A is involved in activating mast cells through its association with Fc receptor $\gamma$ chain. J. Exp. Med. 188:991-995.

10. Yamashita, Y., Ono, M., and Takai, T. 1998. Inhibitory and stimulatory functions of paired Ig-like receptor (PIR) family in RBL-2H3 cells. J. Immunol. 161:4042-4047.

11. Kubagawa, H., et al. 1999. Biochemical nature and cellular distribution of paired immunoglobulin-like receptors, PIR-A and PIR-B. J. Exp. Med. 189:309-317.

12. Taylor, L.S., and McVicar, D.W. 1999. Functional association of FcERI $\gamma$ with arginine ${ }^{632}$ of paired immunoglobulin-like receptor (PIR)A3 in murine macrophages. Blood. 94:1790-1796.

13. Bléry, M., et al. 1998. The paired Ig-like receptor PIR-B is an inhibitory receptor that recruits the protein-tyrosine phosphatase SHP-1. Proc. Natl. Acad. Sci. USA. 95:2446-2451.

14. Maeda, A., Kurosaki, M., Ono, M., Takai, T., and Kurosaki, T. 1998. Requirement of SH2-containing protein tyrosine phosphatases SHP1 and SHP-2 for paired immunoglobulin-like receptor B (PIR-B)mediated inhibitory signal. J. Exp. Med. 187:1355-1360.

15. Maeda, A., et al. 1999. Paired immunoglobulin-like receptor B (PIRB) inhibits BCR-induced activation of Syk and Btk by SHP-1. Oncogene. 18:2291-2297.

16. Chen, C.C., Stephan, R.P., Kubagawa, H., and Cooper, M.D. 1999. Expression of paired immunoglobulin-like receptors, PIR-A and PIRB, by hemopoietic stem cells and lymphoid progenitors. FASEB J. 13:A965. Abstr. no. 707.1

17. Ho, L.H., Uehara, T., Chen, C.C., Kubagawa, H., and Cooper, M.D. 1999. Constitutive tyrosine phosphorylation of the inhibitory paired Ig-like receptor PIR-B. Proc. Natl. Acad. Sci. USA. 96:15086-15090.

18. Gordon, J.R. 1997. FceRI-induced cytokine production and gene expression. In IgE receptor (FcERI) function in mast cells and basophils. M.M. Hamawy, editor. R.G. Landes Company. New York, New York, USA. 209-242.

19. Kozlowski, M., et al. 1993. Expression and catalytic activity of the tyrosine phosphatase PTPIC is severely impaired in motheaten and viable motheaten mice. J. Exp. Med. 178:2157-2163.

20. Asai, K., et al. 2001. Regulation of mast cell survival by IgE. Immunity. 14:791-800. 
21. Nishikawa, S., et al. 1991. In utero manipulation of coat color formation by a monoclonal anti-c-kit antibody: two distinct waves of $c$-kitdependency during melanocyte development. EMBO J. 10:2111-2118.

22. Rolink, A., Melchers, F., and Andersson, J. 1996. The SCID but not the $R A G-2$ gene product is required for $\mathrm{S} \mu-\mathrm{S} \varepsilon$ heavy chain class switching. Immunity. 5:319-330.

23. Bruhns, P., Marchetti, P., Fridman, W.H., Vivier, E., and Daëron, M. 1999. Differential roles of $\mathrm{N}$ - and C-terminal immunoreceptor tyrosine-based inhibition motifs during inhibition of cell activation by killer cell inhibitory receptors. J. Immunol. 162:3168-3175.

24. Razin, E., et al. 1984. Interleukin 3: a differentiation and growth factor for the mouse mast cell that contains chondroitin sulfate E proteoglycan. J. Immunol. 132:1479-1486.

25. Takai, T., Li, M., Sylvestre, D., Clynes, R., and Ravetch, J.V. 1994. FcR $\gamma$ chain deletion results in pleiotropic effector cell defects. Cell. 76:519-529.

26. Lobell, R.B., et al. 1993. Intracellular degradation of Fc $\gamma$ RIII in mouse bone marrow culture-derived progenitor mast cells prevents its surface expression and associated function. J. Biol. Chem. 268:1207-1212.

27. Dombrowicz, D., et al. 1997. Absence of FceRI $\alpha$ chain results in upreulation of Fc $\gamma$ RIII-dependent mast cell degranulation and anaphylaxis: Evidence of competition between FceRI and Fc $\gamma$ RIII for limiting amounts of FCR $\beta$ and $\gamma$ chains. J. Clin. Invest. 99:915-925.

28. Ono, M., et al. 1997. Deletion of SHIP or SHP-1 reveals two distinct pathways for inhibitory signaling. Cell. 90:293-301.

29. Nadler, M.J.S., Cohen, B., Anderson, J.S., Wortis, H.H., and Neel, B.G 1997. Protein-tyrosine phosphatase SHP-1 is dispensable for Fc $\gamma$ RIIB- mediated inhibition of B cell antigen receptor activation. J. Biol. Chem. 272:20038-20043.

30. Gupta, N., et al. 1997. Negative signaling pathways of the killer cell inhibitory receptor and FcyRIIb1 require distinct phosphatases. J. Exp. Med. 186:473-478.

31. Daëron, M., Malbec, O., Latour, S., Arock, M., and Fridman, W.H. 1995. Regulation of high-affinity IgE receptor-mediated mast cell activation by murine low-affinity IgG receptors. J. Clin. Invest. 95:577-585.

32. Katz, H.R., et al. 1996. Mouse mast cell gp49B1 contains two immunoreceptor tyrosine-based inhibitory motifs and suppress mast cell activation when coligated with the high-affinity Fc receptor for IgE. Proc. Natl. Acad. Sci. USA. 93:10809-10814.

33. Takai, T., Ono, M., Hikida, M., Ohmori, H., and Ravetch, J.V. 1996 Augmented humoral and anaphylactic responses in Fc $\gamma$ RII-deficient mice. Nature. 379:346-349.

34. Daëron, M., et al. 1995. The same tyrosine-based inhibition motif, in the intracytoplasmic domain of Fc $\gamma$ RIIB, regulates negatively BCR-, TCR-, and FcR-dependent cell activation. Immunity. 3:635-646.

35. Xu, R., and Pecht, I. 1999. The mast cell function-associated antigen, a new member of the ITIM family. Curr. Top. Microbiol. Immunol. 244:159-168.

36. Liénard, H., Bruhns, P., Malbec, O., Fridman, W.H., and Daëron, M. 1999. Signal regulatory proteins negatively regulate immunoreceptordependent cell activation. J. Biol. Chem. 274:32493-32499.

37. Ott, V.L., and Cambier, J.C. 2000. Activating and inhibitory signaling in mast cells: New opportunities for therapeutic intervention? J. Allergy Clin. Immunol. 106:429-440. 